\title{
El barrio como vestigio del pasado en la narrativa peruana moderna: Barrio de broncas, de José Antonio Bravo, y Final del Porvenir, de Augusto Higa*
}

\section{NEIGHBORHOOD AS A TRACE OF THE PAST IN PERUVIAN MODERN NARRATIVE: BARRIO DE BRONCAS, BY JOSÉ ANTONIO BRAVO, AND FINAL DEL PORVENIR, BY AUGUSTO HIGA}

Alejandro Susti

Universidad de Lima

asusti@ulima.edu.pe

Este artículo examina las novelas Barrio de broncas (1971), de José Antonio Bravo (1937-2016), y Final del Porvenir (1992), de Augusto Higa (1946), como representaciones del espacio del barrio en el que se encarnan códigos de conducta y un ethos cuya existencia se encuentra en riesgo frente a la inestabilidad de la vida moderna y la imagen expansiva de la urbe. Los textos examinados son portadores de las tensiones y contradicciones de una sociedad que debe hacer frente a las nuevas demandas sociales que cuestionan el modelo del progreso. Cercada por la imperiosa presencia de los migrantes andinos, en ellos se representa una Lima condenada a desaparecer.

PALABRAS CLAVE: Lima y la modernidad, narrativa urbana, imaginario urbano, tiempo/espacio en la ciudad, migración y subjetividades
This essay examines the novels Barrio de broncas (1971), by José Antonio Bravo (1937-2016), and Final del Porvenir (1992), by Augusto Higa (1946), as images of the notion of neighborhood, a space in which codes of behavior and ethos are in risk facing the instability of modern life and the expansive image of the city. These texts brought upon the tensions and contradictions of a society that faces new social demands that undermine the model of progress. Surrounded by the overwhelming presence of andean inmigrants, an image of Lima is doomed to extinction in these narratives.

KEYWORDS: Lima and modernity, urban narrative, urban imaginaries, time/space in the city, migration and subjectivities

\footnotetext{
* Esta investigación ha sido realizada con el apoyo del Instituto de Investigación Científica (IDIC) de la Universidad de Lima.
} 
La presencia del barrio como unidad espacial y escenario de una ficción adquiere importancia en la medida en que permite comprender mejor el vínculo de pertenencia de un grupo de pobladores a una zona urbana específica sometida a las continuas presiones de un entorno cambiante'. En tal sentido, el barrio como concepto representa una visión del mundo configurada con autonomía, a la vez que un vestigio del pasado, la huella de un tiempo que se niega a desaparecer rodeado por las evidencias de un presente tangible y un futuro inminente, un anclaje perdido en medio de los vaivenes de una época en crisis. En él, por otra parte, se encarnan ciertos códigos de conducta y modos de hacer, un ethos cuya existencia se encuentra en riesgo frente a la inestabilidad de la vida moderna. En la narrativa peruana del siglo xx, el barrio ocupa un lugar privilegiado, pues opera a la manera de una bisagra en la que convergen el pasado y el futuro, un espacio en el que la historia ha dejado sembradas sus marcas, pero por el que ya transitan el olvido y la muerte.

En este artículo prestaré atención a dos novelas distanciadas por un lapso de dos décadas en las que se reproducen algunos de los rasgos mencionados. A pesar de que sus autores, José Antonio Bravo (1937-2016) y Augusto Higa (1946), pertenecen a dos generaciones distintas, en sus textos se puede reconocer una serie de elementos recurrentes: la presencia de un narrador testigo que evoca con cierta nostalgia un mundo del cual ha participado y que en el presente de la narración se encuentra en vías de desaparición; la descripción de prácticas, rituales y modos de hacer de una colectividad, así como personajes en torno a los cuales se crean leyendas o mitos y con quienes surge $o$ no una identificación posterior entre los miembros de esas colectividades.

\section{BARRIO DE BRONCAS: LA CIRCULARIDAD DE LA HISTORIA}

Fechada por su autor en 1968 y publicada en 1971, Barrio de broncas, novela de José Antonio Bravo, recibió el Premio Nacional de Novela en 1973. Estructurada de manera fragmentaria, como otras novelas de autores peruanos vinculadas al universo de la urbe ${ }^{2}$, la narración da cuenta de un conjunto de historias paralelas que progresivamente se van entretejiendo y en las que destaca el protagonismo del balneario de Chorrillos, situado al sur de Lima. Aun cuando ciertos fragmentos se remontan a acontecimientos ocurridos antes de la llegada de los conquistadores españoles, durante la colonia e, incluso, la

1 “Un barrio es una subdivisión de una ciudad o pueblo, que suele tener identidad propia y cuyos habitantes cuentan con un sentido de pertenencia. Un barrio puede haber nacido por una decisión administrativa de las autoridades, por un desarrollo inmobiliario (por ejemplo, un barrio obrero creado alrededor de una fábrica) o por el simple devenir histórico" (Pérez Porto y Gardey, 2013).

2 Solo mencionaremos Los hijos del orden, de Luis Urteaga (1940-2020); Los aprendices, de Carlos Eduardo Zavaleta (1928-2011); Cambio de guardia, de Julio Ramón Ribeyro (1929-1994); y Patíbulo para un caballo, de Cronwell Jara (1949). 
guerra del Pacífico, la ficción se desarrolla principalmente a lo largo de la primera mitad del siglo xx hasta mediados de la década de 1960. Quien asume la narración es un joven habitante del balneario y testigo presencial de los hechos, Miguel Bardales, hijo de una familia de clase media baja procedente de Miraflores, la cual es obligada a desalojar el predio que habita cuando el protagonista es aún un niño. De esta manera, el relato se inicia con un desplazamiento hacia la periferia de la ciudad, un entorno en decadencia anteriormente habitado por la oligarquía limeña y un pueblo de pescadores, como refiere la bisabuela del narrador, sobreviviente de la guerra:

Quince años tenía yo cuando la guerra. El balneario era una ciudad de alcurnia y estilo. Cuando hacíamos paseos al cerro, desde lo alto, mirábamos la uniforme chatura de sus techos de barro y claraboyas. Claro que existía el Alto Perú, pescadores decentes todos, negros, indios y mulatos, pero con estilo y decencia. (Bravo, 1996, p. 76)

La guerra, sin embargo, es solo un capítulo más en la larga cadena de crisis y catástrofes que sufre el balneario a lo largo de su historia3: la irrupción de fenómenos naturales -terremotos, inundaciones-, la devastación y muerte producidas por la guerra o la explotación esclavista, así como la violencia del presente, generan la sensación en el lector de estar presenciando la historia de un pueblo que una y otra vez renace de sus cenizas. En Chorrillos, a la manera de los míticos Macondo o Comala -escenarios de Cien años de soledad y Pedro Páramo, respectivamente-, convergen todos los tiempos y espacios: prácticas artesanales anteriores al contacto del Nuevo Mundo con la civilización occidental -la más evidente de todas ellas, la pesca-; escenarios naturales -el mar, las playas de La Herradura y Agua Dulce, los acantilados de la costa y la laguna de Villa-; restos de ruinas incaicas; vestigios de la guerra del Pacífico; casonas aristocráticas republicanas; una iglesia colonial —en la hacienda Villa-y, por último, una escuela militar. Chorrillos es, además, escenario de la celebración de una fiesta religiosa católica de profundo arraigo popular -el 29 de junio, Día de San Pedro y San Pablo-y de los carnavales del mes de febrero.

En esta historia cíclica de ascensos y caídas, la modernidad hace su aparición a inicios del siglo xx, una belle époque que históricamente coincide con el Chorrillos descrito por la protagonista de Cartas de una turista, la novela de Enrique Carrillo (1877-1936):

Calles empedradas y faroles a gas. Jardines públicos rodeados con rejas de fierro al estilo inglés. Lecheros con sus carretas y caballos percherones. Sombrillas

3 En la novela también se incorpora en ciertos pasajes a quienes habitaron en la época incaica o durante la colonia, como sucede con los esclavos negros de la hacienda Villa en el siglo XVII, al sur de Chorrillos, que cortaban "las canteras del morro uno tras otro, los geométricos bloques, sólidas moles", destinados a la construcción de obras como el "puente de Piedra encima del río Rímac" (Bravo, 1996, p. 46). 
de madera en cada banca del malecón. Celosías y mamparas entreabiertas a la curiosidad. Y después la Escuela Militar resurgiendo bajo la dirección francesa del general Clement. Limoneros y viñedos, girasoles, manzanos y platanares rodeaban al pueblo amurallándolo con su fragancia. (Carrillo, 2007, pp. 99-100)

Sin embargo, como señala uno de los protagonistas, don José Ugaz, exdirector del Colegio Nacional:

-El balneario no es la suma de anécdotas, no es tampoco la gente pintoresca que ha pasado por aquí, ni su historia. Es algo más: lo que hay detrás de cada rostro, lo que sucede detrás de cada puerta, lo que solo la noche contempla cuando el silencio y el sueño se confabulan, lo que se dice en baja voz, al oído, lo que sordamente va creciendo en un pueblo. (Bravo, 1996, p. 27)

El uso del término pueblo, por oposición a las denominaciones de balneario o distrito producto de delimitaciones políticas y circunstancias históricas, se relaciona con el mito, es decir, con una dimensión ahistórica y poética situada más allá de los confines del tiempo. Significativamente, esta otra dimensión aparece estrechamente ligada a la vida del narrador-protagonista, Miguel, único personaje de la ficción que intenta sustraerse de los condicionamientos que limitan al resto de sus pares a través de su interés por la poesía y la escritura que representan, en última instancia, la posibilidad de trascender el fracaso y el determinismo imperantes; de este modo, el vínculo con la creación poética le permite a Miguel en la segunda parte de la novela entrar en contacto con artistas y personajes de la bohemia con quienes comparte diversas experiencias - sesiones de misa negra, happenings, fiestas, entre otras-y, en general, lo que él describe como el mundo de la "nocturnidad" que, en algún modo, enriquece su visión de la vida y lo libera del mundo cerrado y arcaico del balneario ${ }^{4}$. Ese contacto, por ejemplo, le permite conocer a amigos como Fernando, el pintor Ambrac y Mónica, mujer con la que establece una relación de pareja y quien, además, lo motiva a escribir:

La verdad es que nunca habías reparado en serio en alguna mujer de la nocturnidad y esa noche luego de esa larga espera, de ese interminable aburrimiento de la casa de Fernando, llegó con él Mónica y todo comenzó a cambiar, creo que eso fue lo que tú sentías que faltaba o tal vez eran los nervios, porque hacía muchos días que no fumabas. Pero no. En el fondo lo importante fue encontrarte con Mónica, comprenderla fue más interesante todavía y esa noche escribiste por fin tu poema Grietas. (Bravo, 1996, p. 168)

La experiencia es narrada retrospectivamente y mediante la adopción de la segunda persona, rasgo que prevalece a lo largo de la segunda parte de la novela en la que adquieren mayor protagonismo la subjetividad y el mundo interior del protagonista.

4 Para ese entonces, el protagonista ha sido expulsado de la casa paterna. 
Esta variante narrativa genera, por otra parte, el efecto de un paréntesis en la agobiante precariedad que gobierna la vida del balneario. Así, por ejemplo, Miguel se plantea la posibilidad de escribir una novela con base en el interés que suscita en él el trabajo de Ambrac:

Allí nacía un cuadro. Allí fue cuando te comenzaron a crecer las ganas de escribir una historia entre pintura y literatura. Renacer a la vida en la creación. Eso era lo que querías. Tú querías que cada personaje tuviera un color, cuya vinculación con el cuadro que acababa de pintar Ambrac fuera tal que el erotismo, la decadencia y el delirio por la creación se alambicaran en el contexto, postulando la realización de un relato que en el fondo fuera él mismo. (Bravo, 1996, p. 169)

Se trata, ciertamente, no solo del despertar de la vocación artística en el personaje, sino de la posibilidad de educarse a través del arte, aproximación que vincula fugazmente la novela con el género del bildungsroman: el hecho de poder "renacer" a la vida que le brinda el arte a Miguel y la posibilidad de desarrollarse como individuo lo colocan en un lugar privilegiado, por oposición a aquellos jóvenes del balneario sometidos a las carencias e impulsos autodestructivos que gobiernan sus vidas; en cierta medida, las peripecias de Miguel funcionan a la manera de una alegoría del individuo a quien se le ofrece la oportunidad de ser libre a pesar del entorno social. A este deseo de explorar su faceta como creador, incluso, se agregará el proyecto compartido con Mónica de viajar al exterior, a estudiar en Salamanca, España. En Miguel, por otra parte, las huellas de la presencia del artista adolescente surgen a través de la continua evocación del paisaje del balneario, aun cuando se desplaza a través de las calles del centro de la ciudad:

La creación era importante entonces, caminabas las calles pensando tu poesía, sintiéndola, mirando, saboreando las formas que el amanecer te daba. Ya no ibas al balneario, pero recordabas la luz cayendo abierta y limpia en el verano, los patillos alzándose picudos hacia el morro. (Bravo, 1996, p. 170)

En los extensos pasajes en los que el personaje evoca la contemplación de la naturaleza destaca, por ejemplo, el interés que despierta en él el naufragio del Caplina, ocurrido en una playa cercana a La Herradura. El barco hundido, para él, es también una metáfora de la lucha entre la vida y la muerte: "Veías al Caplina, inclinado como un guerrero griego caído por el cansancio, esperando con un gesto extrañamente victorioso la terminante mordedura de la muerte" (Bravo, 1996, p. 171). Esta brecha o apertura en la vida del protagonista, representada por el deseo de desarrollar su sensibilidad como artista, sin embargo, será fugaz y se prolongará solo hasta poco después del abrupto deterioro de su salud, producto de los síntomas de una tuberculosis que hará que sea recluido en un sanatorio en el pueblo de Chosica, situado en el camino a la sierra central del país. Allí, la debilidad física y la abulia impedirán, finalmente, que lleve a cabo su proyecto creativo. 
No obstante, las peripecias de Miguel y sus exploraciones en el dominio de la creación artística constituyen una excepción en contraste con los vaivenes de la historia de Chorrillos y las urgencias que determinan la vida de sus habitantes. Abandonado por las autoridades políticas, el destino del balneario recae en manos de dos grupos que se disputan el control de sus calles e instauran en ellas el reino de la violencia y la barbarie. Paradójicamente, sus miembros provienen del mismo colegio y comparten la pasión por el fútbol, lo cual los lleva a enfrentarse sin tregua a lo largo de tres décadas:

Es cierto que el balneario ha cambiado, que cerca a [sic] las ruinas de Armatambo hay tres barriadas, en Villa más de cuatro y el barrio fiscal ha crecido, además de las urbanizaciones nuevas. Cuenta mucho la gente, es cierto, pero quienes deciden la vida del balneario son los del Tabaco y el Alto, dueños y señores de las playas, los cerros, el municipio, las instituciones y hasta la Acción Católica y la iglesia. (Bravo, 1996, p. 135)

Obligados por las circunstancias, los jóvenes luchan, además, por sobrevivir en un mundo hostil en el que no encuentran mayores motivaciones. Muchos de ellos se prostituyen, alcoholizan, viven al margen de la ley o acaban como Jaime Peralta, un investigador de la policía que llega a formar una familia, pero que, finalmente, es dado de baja al comprobarse sus vínculos con una mafia de contrabandistas de joyas. Sometida a la rutina y el tedio, la vida de Peralta se traza indefectiblemente como sucede con el recorrido del tranvía que cada noche lo traslada al balneario:

Casi diez años después del terremoto del 40, Jaime Peralta seguía haciendo, con regular puntualidad, su recorrido en tranvía desde el paradero de la Exposición hasta el último del balneario. Largos tres cuartos de hora, durante el viaje nocturno, por entre los sembríos de algodón, los pepinales, largas hileras de girasoles y hasta establos. Cuando el tranvía llegaba a Miraflores, sentía que había cumplido la mitad de su recorrido, y entonces, le parecía que todo era como en bajada. (Bravo, 1996, p. 66)

El desplazamiento se realiza desde el centro de la ciudad hacia su periferia: situado en los márgenes de la urbe, Chorrillos es un espacio alejado del trajín y las atracciones de la vida moderna en pleno siglo xx y que acusa el atraso propio de las zonas más apartadas. El itinerario, sin embargo, no se debe al hecho de que Peralta retorne a su hogar para encontrarse con su esposa, Marita, sino al apego que siente por la Tira del Tabaco, una de las bandas que dominan las calles del balneario (Bravo, 1996, p. 68). Esta atracción, sumada a su falta de aspiraciones, habrá de conducir al personaje a convertirse en un alcohólico y un paria.

Como símbolo de la modernidad, la historia del tranvía está también estrechamente emparentada con Chorrillos: 
En la cantina, don Pedro Balandra nos contó la historia del tranvía desde 1905, con lujo de detalles pasó por 1930 cuando los acoplados, y posteriormente en el 45 con los de puerta automática. Su compadre Temoche, de Surquillo, trabajó 40 años en la compañía y las sabía todas, así es que por eso estaba enterado. (Bravo, 1996, p. 121)

El tranvía, sin embargo, metaforiza en la novela el fracaso del proyecto de modernizar la ciudad: "Mientras comentábamos cómo le había podido robar tanta playa el club Regatas de la de Pescadores, alguien me contó que la orden de finiquitar los tranvías se había dado. El gobierno" (Bravo, 1996, p. 121). La muerte del tranvía marca un hito más en la larga cadena de abandono y aislamiento del balneario, y con ella se cierra otro ciclo; como se constata en numerosos pasajes de la novela, sus vías proponen un itinerario que da cuenta de la extensión del perímetro de la urbe, a la vez que acompaña las meditaciones de los personajes, como sucede en el caso de Miguel: "Has tomado el tranvía y en su interminable ruta de postes de madera has sentido cómo te crucifica el tiempo, sin salida ni posibilidades" (Bravo, 1996, p. 157). La asimilación del tranvía a la subjetividad del personaje es una prueba del estrecho vínculo entre sujeto y máquina, así como de su presencia en el imaginario colectivo y la vida cotidiana del habitante de la ciudad.

En el devenir histórico del balneario existen, por otra parte, dos hitos fundamentales. El primero de ellos es el terremoto de 1940, tempranamente representado en la novela a través de la memoria del protagonista:

Las torres de la iglesia tiemblan, los gritos se abren paso entre la gente.

\section{$[\ldots]$}

Corro al malecón hundido en la impotencia de mi llanto. El mar sube, el barranco cede. Los botes al garete. Tiembla el temor en cada rostro. Mi madre ahogándose en un grito al fondo de la calle. Corro a la plazuela, caigo en el cascajo [...]. La casa gris de frente a la iglesia soporta impasible la sorda persecución de los temblores. El morro se desintegra. Me encuentro entre gente desconocida, en calles desconocidas, pedregosas, irrespirables. El mar ha cubierto el malecón, los árboles navegan, caen las casas, las torres de la iglesia caen. Imposible subir al morro a guarecerse $^{5}$. (Bravo, 1996, pp. 16-17)

5 Páginas adelante, el evento es también representado desde el punto de vista de otro personaje de la novela, Juan de Dios, hijo de doña Temblores Alcázar, mujer dotada del poder de la clarividencia: "Pero Juan de Dios entendió recién, la noche del 23 de mayo del 40, que al día siguiente el presagio se cumpliría con mayores infortunios. La paloma que doña Temblores llevaba siempre en el pecho había muerto. Por eso, cuando la clarividente entró en la casa y prendió - por primera vez en la vida de Juan de Dios - todas las luces, el niño, aún soñoliento, pudo observar la augusta congoja en el rostro agrietado de su madre" (Bravo, 1996, p. 24). 
La escena reproduce la confusión y el dramatismo causados por la violencia del cataclismo. Colocado al inicio de la novela, el poder devastador del evento es también un anticipo de la inestabilidad y fragilidad que dominan la vida de los habitantes del balneario y un anuncio de las penurias a las que parecen estar condenados. Para la familia, por otra parte, es la confirmación del declive de sus aspiraciones: una vez desalojada de la quinta de Miraflores, deberá soportar las adversidades que habrán de acompañarla de ahí en adelante. Asimismo, el efecto del terremoto en la historia de Chorrillos habrá de repercutir como un umbral que marca "el antes y el después", como refiere don Pancho, antiguo guardián de la bomba Garibaldi, en sus tertulias con el director Ugaz, ya retirado, y don Pedro, portero de la escuela 443: "Los verdaderos señores ya dejaron el balneario, desde el terremoto comenzaron a irse, y eso hace más de veinticinco años. Hasta los Riva Agüero, claro que su fortuna la dejó don José a la universidad" (Bravo, 1996, p. 50). De esta manera, otra de las consecuencias del terremoto es la recomposición del tejido social del balneario, así como la depreciación de las propiedades y la consecuente pauperización de sus habitantes. Por otra parte, la adversidad no produce en el balneario los efectos que, por ejemplo, desea don José Ugaz para sus alumnos: “Tenemos que trabajar juntos para levantar al pueblo de la ruina y el desorden, y ustedes, niños, alumnos, no pueden originar más calamidades, enfrentándose en las calles y complicándole [sic] la vida a sus padres" (Bravo, 1996, p. 70). La perorata del director, en realidad, no parece dirigirse solamente a los estudiantes, sino al conjunto de la sociedad chorrillana: es una exhortación a abandonar los conflictos y disputas del pasado que, a la larga, han producido la decadencia y el caos imperantes.

Un cariz diferente asume el segundo evento crucial de la novela, el golpe militar de 1948, liderado por el general Odría:

Cuando nos dirigíamos a los techos que llevan a la cúpula, un montonal de aviones pasaron por encima de nuestras cabezas, en dirección al mar; los miramos largo rato más allá de la bahía. Bien en picada alguna de sus vueltas. Pirueteando estuvieron. Pero cuando llegamos a la cúpula y mirábamos el interior de la iglesia, un ruido sordo de camiones nos llamó la atención. En el malecón una hilera enorme de soldados parapetados detrás de los muros y otro montonal que llegaba en camiones, jeeps y hasta motocicletas. "Maniobras", dijo Panetón. Y allí estuvimos sobre la marcha.

[...]

Abajo, en el mar cuatro cruceros en plan de mover sus cañones. Y largavista con los generales. $Y$ mensaje con luces y banderolas. $Y$ los pescadores como si nada. Y moviéndose suaves, lentos, precisos, los cañones de los barcos, moviéndose. (Bravo, 1996, pp. 42-43)

La exhibición del poder militar representado desde la perspectiva de los dos niños relativiza las consecuencias del levantamiento; sin embargo, en el conjunto de la novela 
es una demostración de la inestabilidad política de la época y la debilidad del régimen democrático del momento. A diferencia de Los aprendices, novela de Carlos Eduardo Zavaleta, en donde se representa el mismo episodio desde el punto de vista de los estudiantes sanmarquinos que se oponen a la imposición del régimen militar, en Barrio de broncas las consecuencias del golpe tienen una relativa presencia en el desarrollo de la historia ${ }^{6}$; es más, las remodelaciones que posteriormente llevan a cabo los militares en el balneario suscitarán la simpatía de los chorrillanos ${ }^{7}$. En todo caso, solamente cuando Miguel, el protagonista, se incorpora a la vida universitaria - con poco o nulo éxito-. parece nacer en él una conciencia política:

Las palmeras del Parque Universitario. La casona vieja, el viejo local de la U, con su vozarrón de marcas y gritos histéricos desde sus altoparlantes. Los policías al frente, escondidos en el corralón de la marmolería. Todo como siempre, como hace tres años cuando entraste a la facultad. Te acuerdas de lo que te dijeron los viejos, que así había sido en el 45 cuando los apristas, igual también en el 48 cuando Odría. Lo mismo en el 51. En el 56, cuando Mendoza le cambió el poder a Prado. Te acuerdas que fue igual, no importa cuándo. Pero fue igual. Y piensas, las mismas tácticas siempre, los guardias tiran palazos y gases lacrimógenos. (Bravo, 1996, p. 158)

No obstante, la repercusión de los eventos políticos en él es mínima y más bien sus intereses se encaminan ya sea por la vida bohemia, la cual lo lleva a conocer el centro de la ciudad, o por su trabajo de vendedor de libros en distintas ciudades del país. En todo caso, el escenario político, de acuerdo con el pasaje citado, reproduce la circularidad de la historia del balneario y la incapacidad de sus habitantes de sustraerse de ella: terremotos, aniegos y golpes militares se repiten sin que se vislumbre la posibilidad de un cambio o ruptura con el pasado.

En términos de espacio, el malecón del balneario opera a la manera de un palco desde el que se presencian los principales acontecimientos de la novela, así como la vista del mar, las maniobras de los soldados de la escuela militar o las celebraciones por la fiesta de San Pedro y San Pablo. Su inestabilidad, sin embargo, es también un signo de la precariedad del balneario: como umbral que separa el pueblo y la playa situada metros abajo, es el límite entre el espacio social y una naturaleza indomable cuyo poder destructivo se evidencia en los terremotos y maretazos que afectan a las embarcaciones

6 La excepción es la situación de Panetón, compañero del protagonista, cuyo padre - aparentemente un militante aprista- es encarcelado en la isla del Frontón: "Panetón ayudó ese día, pero ya hacía tiempo estaba triste porque a su viejo lo habían guardado en la isla de San Lorenzo [sic]. Él me dijo que por política y yo no entendí muy bien el asunto" (Bravo, 1996, p. 44).

7 “'El balneario será como antes' [...]. 'Qué bien ha quedado la iglesia' [...]. 'Qué buenos los militares de la Revolución, nos están arreglando el balneario'. En cuatro meses cambió la cara del pueblo" (Bravo, 1996, p. 86). 
de los pescadores. Asimismo, existen otros espacios desde los cuales los personajes de la novela disponen de la posibilidad de contemplar el balneario y el paisaje del resto de la ciudad, como ocurre con los paseos que realiza Miguel, mencionados anteriormente:

Regresabas al pasado y te veías paseando por el cerro, caminando lentamente, rítmicamente, respirando acompasadamente "para fortalecer tus bronquios". $Y$ desde arriba, para ti los techos del balneario, los techos pueblerinos y chatos y terrosos de tu barrio. Tú mirabas los techos desde arriba; las palmeras de la Plaza Matriz se alzaban viejas y enclenques; en el parque Castilla, los ficus altos y añosos. Las claraboyas encima del barro seco de la techumbre. La gente pequeñísima, dirigiéndose, regresando. La hilera de pinos de la bajada del Agua Dulce, las trepadoras y enredaderas de los chorrillos de la playa, aquellas filtraciones de agua purísima en la base de los barrancos. Las buganvillas moradas cayendo desde el refilo del malecón, como asomándose sigilosas al mar. La playa abierta y calma esta madrugada en que se ha dado por venir tan arriba, desde donde la neblina detenida en el horizonte, calla. (Bravo, 1996, p. 177)

Contemplado desde la distancia y lo alto, el balneario irradia una belleza totalmente ajena a las realidades que día a día se desarrollan en él; la calma y la armonía que despierta en el paseante el paisaje contrastan notablemente con lo que sucede en sus calles. El pasaje, sin embargo, es útil en la medida en que la ausencia del conflicto social hace posible la emergencia de una belleza poética y atemporal, es decir, de la imagen de la aldea idílica. De manera similar a como serían representados en una pintura paisajística, los habitantes del balneario son solo figuras "pequeñísimas" perdidas en la lejanía espacial y en la memoria del protagonista; en todo caso, seducido por la belleza del panorama, el espectador debe abocarse a la tarea de explorar aquellos significados que permanecen ocultos a su mirada o más allá del marco de la representación. En tal sentido, la ausencia de marcas que evidencien el tiempo humano y las circunstancias en que se ha realizado la "pintura" son una invitación a adoptar una mirada crítica frente a lo representado: lo que "no está" es precisamente lo que debería sugerir la búsqueda del significado para el crítico u observador.

La novela, finalmente, se cierra con otro episodio cíclico de consecuencias nefastas: el aniego producido por la acequia de la escuela militar en la que es encontrado el cadáver de Lejos y Medio, un muchacho víctima de la violencia imperante en el balneario:

Rotas las tuberías de los desagües y atorado el boquerón de la acequia de la Escuela, la correntada y el hedor crecían a pasos agigantados. Pronto se vio a todo el pueblo sacando sus muebles a la calle, colocándolos unos encima de otros, procurando salvar algo. La desesperación, los gritos, el movimiento, los avemarías, el miedo y los llantos de los niños crearon el pánico y el desorden. (Bravo, 1996, p. 233)

Esta vez, sin embargo, la adversidad genera una respuesta distinta entre las bandas del Alto y el Tabaco, quienes están a punto de enfrentarse en otra sangrienta contienda: 
sus integrantes dejan de lado sus rivalidades para auxiliar a las víctimas de la inundación (Bravo, 1996, p. 233); entre estas últimas, no obstante, se identifica al exdirector del colegio cuya muerte puede ser entendida como un sacrificio necesario para que surja la solidaridad entre sus alumnos que tanto pregonó en vida. Este final reconciliador es al menos un síntoma de que la larga cadena de desgracias sufridas por el pueblo podrá ser rota en el futuro, aunque estos aún sigan "mirándose de reojo": "Por primera vez los del Alto y el Tabaco, abrazados, cargando los ataúdes, tranquilos y tristes, pero midiéndose, por si acaso, mirándose de reojo, midiéndose" (Bravo, 1996, p. 234).

\section{FINAL DEL PORVENIR, DE AUGUSTO HIGA}

Publicada en 1992, Final del Porvenir se ambienta en la Lima de los años cincuenta8, época en la que también se sitúa parcialmente la novela de Bravo. Sin embargo, la novela de Higa transcurre casi en su totalidad en el populoso distrito de La Victoria, inicialmente diseñado como un barrio obrero":

La Victoria era un enorme distrito color del hormigón, en los extramuros de la ciudad, en los límites de los algodonales, muy cerca a los disminuidos establos, en las proximidades de los canchones de alfalfa, y todavía se respiraba el aire de los eucaliptos. (Higa, 2007, p. 7)

Utilizando la primera persona, como ocurre en Barrio de broncas, el narrador reconstruye retrospectivamente un mundo ya extinguido desde la perspectiva de un testigo presencial; por ello, el título puede ser leído no solo como una alusión al barrio en el que se desarrollan las acciones, sino al final de una etapa de la vida del narrador marcada por los fuertes lazos afectivos que lo unen a quienes, como él, habitaron un edificio multifamiliar o unidad vecinal:

Nosotros vivíamos en esos edificios multifamiliares, y recuerdo su aspecto de madrigueras, aquellas oscuras galerías, los rústicos balcones, los tenebrosos pasadizos y los cientos de ventanucos alrededor de las paredes. Sí, una verdadera

8 La única referencia cronológica aparece al inicio de la novela: “Lo recuerdo: era el año 1954” (Higa, 2007, p. 11).

9 Sobre los orígenes de La Victoria, escribe Ramón Joffré (2014): “En el gobierno de José Balta, se destruyeron las murallas de Lima y el ingeniero Luis Sadá elaboró un visionario Plano topográfico (1872) que muestra los proyectos emprendidos y sugiere las pautas básicas de los siguientes ciclos constructivos. Entre las reformas entonces imaginadas, se planteó trasladar el centro administrativo limeño al sur, al futuro barrio de La Victoria. La mudanza institucional nunca ocurrió, pero desde inicios del siglo xx una empresa privada se encargó de urbanizar esta zona. Las irregularidades en el proceso constructivo, realizado sin coordinar con la municipalidad, llamaron la atención del público: 'El barrio de La Victoria es de lo más anodino que hay en materia de urbanización. Comenzó como un negocio, sigue como tal y concluirá por desastre' (Dávalos). Según este testigo, La Victoria sería el 'barrio pavoroso de Lima' construido con los 'desechos y las puertas viejas de las casas que se derrumban en el centro de la ciudad'" (p. 77). 
montaña de cemento, con sus cuatro avenidas rodeándola, y la gente que se apelotonaba en las escaleras, los corredores, los patios y los alumbrados públicos. Increíble. Atroz. (Higa, 2007, pp. 7-8)

Rodeado por una zona de la ciudad en la que coexisten todo tipo de comercios - una peluquería, un billar, bares, tiendas, quioscos, mercados, entre muchos otros establecimientos- y en cuyas calles y avenidas se despliega la despiadada e intensa lucha por la supervivencia, el edificio cobija en su interior una multitud de inquilinos, cada uno con su propia historia, expuestos a las vicisitudes de una clase social que lentamente se pauperiza y sufre, finalmente, el desalojo de sus viviendas. Final del Porvenir, en tal sentido, es una novela emparentada con aquellas narrativas que décadas antes abordaron la situación de una clase empobrecida obligada a desplazarse hacia los nuevos márgenes de la ciudad ${ }^{10}$. Por otra parte, el espacio público se configura a la manera de un territorio con el que interactúan y por el que se proyectan las subjetividades de los personajes, lo cual da pie a un sinnúmero de descripciones y referencias a avenidas, calles, mercados, parques y muchos otros espacios públicos con los que se teje una vasta red de significados: el mercado de La Parada, los "tenduchos alineados en la [avenida] Aviación", "la carpa del coliseo Mundial" (p. 31), los "hoteluchos de Gamarra" (p. 42), el "hangar del [Mercado] Mayorista", el "bravo Mendocita", el "barrio de Luna Pizarro", el "abismo de la calle Huatica" en donde "[e]n batas trasparentes, las hembras lujuriosas, enjauladas en ventanales, exhiben los bustos descubiertos" (p. 55), el "bar de Parinacochas" y muchos otros que forman parte de los itinerarios existenciales de los sujetos de la ficción:

El Mácalo y yo vamos empujando. Trazamos un callejón en el mar humano. Ajenos a la mescolanza, indagamos por los reducidores, escondidos en las tolderas de cartón. En general son hoscos, biliosos, de mirada torva. Una mujer llora, tiene un niño en los brazos, jura que le han robado, una cadeneta de plata, dice, le han arrebatado el bolso, y los ladrones han corrido, se han esfumado, no sabe a quién echarle la culpa entre tanta gente y estira la mano esperando la caridad de las personas. Nosotros encontramos al cholo Vento, un experto en harapos, a quien ofrecemos lo que llevo en un costal: plumillas de carro, chapas de cerrajería, alicate y badilejo de albañil. Cincuenta soles en total. Sin regatear un ápice, cerramos el trato. (Higa, 2007, p. 42)

El "mar humano" a través del cual se desplazan los personajes es una acertada metáfora para transmitir la dispersión y desorden de un espacio en constante ebullición: atiborrado de mercancías y objetos de toda clase, en él no hay lugar para la pausa; estridente y sonoro, plástico y caótico, por él se desplaza el ojo del narrador a la manera de una cámara en movimiento, captando los retazos de una realidad solo aprehensible

10 Un ejemplo de ello sería el cuento "Al pie del acantilado", de Julio Ramón Ribeyro, incluido en el volumen Tres historias sublevantes (1964). 
a través de la palabra: de allí el uso recurrente de la enumeración y la frase corta para crear una analogía entre el plano del significante y el carácter del universo representado. Sin embargo, en otros casos, los desplazamientos de los personajes se realizan a la velocidad de un peatón, lo cual permite una captación sonora y visual más completa del entorno, como ocurre con la profusa e intensa descripción de un espacio asociado al comercio sexual, el legendario jirón Huatica ${ }^{11}$, situado a tan solo unas cuadras de la unidad vecinal:

En la penumbra [el señor Piedra] atraviesa el bravo Mendocita, corre presuroso el barrio de Luna Pizarro, y se sumerge en el abismo de Huatica. Poder absorber el ron de quemar, percibir la colonia barata flotando en la atmósfera, mirar los rostros febriles, oír el guitarreo malero de los bares. En batas transparentes, las hembras lujuriosas, enjauladas en ventanales, exhiben los bustos descubiertos. Los matones recorren la periferia. Apenas son cinco o seis calles angostas. Bajo el irreductible aire tibio, las negras pululan en los bares, a lo lejos suenan los bongoseros y las trompetas de las esquinas musicales, en el jirón de las extranjeras, ríen las locas francesitas. (Higa, 2007, p. 55)

El personaje se adentra en un universo que presenta marcas de carácter muy distinto de aquellas que tipifican el espacio del comercio de mercancías y abastos: los olores son ahora sensuales, las expresiones faciales y corporales adquieren connotaciones sexuales, los sonidos se hacen armoniosos y la desinhibida exhibición de los cuerpos despierta en el caminante otro tipo de significados. El jirón Huatica es, sin lugar a dudas, un breve hiato en el panorama monocorde de la ciudad, pero, sobre todo, un espacio destinado a la satisfacción de las pulsiones y deseos sexuales, y a la construcción de la masculinidad y el ejercicio de la sexualidad varonil. Se trata, además, de un espacio de tránsito y fugaz, en el que entran en conflicto las prohibiciones y normas que regulan la sexualidad en la sociedad y la libertad del sujeto a ejercerla. Por otra parte, a pesar de su aparente legalidad, es un espacio criminalizado por la asociación de la prostitución a actividades delictivas como el proxenetismo, el robo o la venta clandestina de drogas.

Un mecanismo narrativo empleado recurrentemente en la novela para dar cuenta de la masa anónima que circula por las calles de La Victoria es la focalización interna, pero no con el fin de dar una visión totalizadora de la experiencia, sino de producir un

11 Sobre los orígenes del jirón Huatica, señala Prieto Sánchez (2009): “La zona urbana conocida como El Veinte, en la calle XX de Setiembre, que guareció por varios años y sin ningún sobresalto al oficio más antiguo del mundo, tuvo su primer revés al tener que variar de nombre debido a la queja de la embajada de Italia, que consideró que se manchaba el significado histórico de esa fecha al equipararlo con un oficio inmoral. El nuevo nombre acordado fue Huatica, debido al brazo del río que pasaba a sus espaldas y que limitaba la ciudad formando siete cuadras desde la Alameda Grau hasta Sebastián Barranca [...]. Pero Huatica no solo fue el nombre referencial de una calle (muchas veces innombrable), sino que se convirtió con el pasar de los años en el más afamado distintivo lúdico-sexual que tuvo el país en el siglo xx" (p. 179). 
discurso fuertemente subjetivizado cuya logicidad y sentido están a punto de quebrarse; un ejemplo de ello son las descripciones de las visiones del tío Américo, personaje que sufre de trastornos mentales, cargador de La Parada' ${ }^{12}$ y habitante de una covacha de esteras en la azotea del edificio en el que se desarrolla la mayor parte de las acciones:

Cruzar el confín de los vivos. No cristianos. No individuos. No personajes. Sin sentir. Nadie conversa. Almas desoladas. Perdidos en los infinitos caminos. Cargan velas ardientes en el hombro. Hundidos en círculos oscuros. Estáticos. Parecen dibujados en piedras, los carniceros no se cansan de tajar morriones. La tropilla de ropavejeros se echa a caminar con sus bultos amarrados a los pies. Lloran los camioneros, no conocen las rutas. Los huérfanos buscan a sus madres en los miles de resplandores. En jaulas se llevan a los enfermos incurables. Los dementes aplastan sus piojos al lado de la carretera. Pelean las yerberas y los fruteros. (Higa, 2007, p. 44)

Las visiones del personaje revelan una dimensión oculta del mundo representado: la aparente vitalidad y movimiento del paisaje urbano son reemplazados por una atmósfera de desolación y pesadilla en la que prevalecen el sufrimiento y desamparo de los transeúntes, lo cual genera una prosa expresionista que, a diferencia del realismo predominante en la narrativa de la generación del 50, coloca en primer plano la subjetividad del personaje ${ }^{13}$. Esta exacerbación de los contornos del mundo desvela las limitaciones del paradigma realista, a la vez que genera una proliferación de los significados del texto, el cual se torna ambiguo y polivalente y, además, configura un narratario muy distinto del postulado por la narrativa realista.

Del mismo modo, en Final del Porvenir lo sobrenatural ocupa un lugar importante dentro la ficción: la transgresión de las leyes que gobiernan la lógica causal de los acontecimientos o las propiedades inherentes de los objetos se hace evidente desde la perspectiva de ciertos personajes; ello ocurre, por ejemplo, con el hermano menor del narrador, el Pelelén, un "auténtico bicho raro, de cuerpo enclenque, ojos adormilados y manías erráticas" (Higa, 2007, p. 28), que concibe el edificio que habita y el Ministerio de Educación del centro de la ciudad como seres con vida propia:

Al descender las escaleras, ya a oscuras a esa hora, a la primera respiración, sentía los quejidos del edificio desprendiéndose de las columnas, las paredes, los ventanucos, y el suelo mismo [...]. Después de todo, hasta los edificios respiraban,

12 En su estudio sobre La Parada, escribe Patch (1973): “Los cargadores están al final de la escala ocupacional. Su única inversión consiste en una plataforma con dos ruedas y dos mangos, sobre la cual acumulan gran cantidad de bolsas y cajones de productos que nunca faltan, llevándolos del intermediario a los dueños de los puestos, de los mayoristas a sus puestos y de estos a los camiones de los vendedores de otros mercados y a los vehículos de los dueños de restaurantes y consumidores" (p. 25).

13 Este rasgo, por otra parte, está también presente en los relatos que conforman Los inocentes, libro de Oswaldo Reynoso (1931-2016). 
palpitaban, exhibían su vientre, mostraban alegrías y penas, y lloran como probablemente lloran las piedras y los árboles. (Higa, 2007, p. 31)

$[\ldots]$

[Pelelén], venciendo el miedo, se acercó jadeante [al Ministerio de Educación], tanteó con las manos el ónix renegrido, abrió la boca, pasó la lengua sobre la pared, cerró los ojos, y dijo pensativo: “Es una mole triste”. (Higa, 2007, p. 150)

A diferencia del discurso subjetivizado del tío Américo, las percepciones del Pelelén expresan una dimensión mágica inédita. Algo similar sucede con "doña Olga, la ruca", madre de familia encargada del cuidado de la gruta de la Virgen del Carmen del patio principal del edificio, quien recibe un día la noticia de que su esposo, don Pepito Vidalón, a quien ha terminado por odiar después de haber compartido con él una vida infeliz, está próximo a morir:

Como un camión salvaje, tumbando puertas, hundiendo ventanas [...]. Así lo sintió doña Olga, la ruca, en la medianoche de un jueves [...]. Una tarde cruzó el jirón América de casualidad, sin que nadie le impidiera consultar a la más avezada de las gitanas [...] quien le confirmó tres veces sus premoniciones: en la palma de la mano, en la lavaza del cielo, y en el fondo de su inconsciente [...]. Regresó al edificio con una aureola sobre la cabeza, en el mercadillo dio vueltas sin sentido, en el patio se arrodilló ante la Virgen, y lloró gozosa. (Higa, 2007, p. 81)

Páginas más adelante, la imagen del "camión salvaje" que representa a la muerte se convierte en un murmullo capaz de desplazarse a través de las calles del barrio:

Pero desde la tarde en que la gitana le confirmó su intuición, algo cambió en su carácter y en su alegría, pues fue soltando la traviesa noticia de una muerte segura. Catastrófica y violenta, narró sus sueños, el camión mortecino avasallaba el edificio, trituraba paredes y ventanas, hundiendo el suelo, sin dejar muro intacto [...]. El murmullo rodó por las escaleras, subió al cuarto piso, se posesionó del mercadillo, rebotó en la panadería Santa Marta, y la ladera de Giribaldi. (Higa, 2007, p. 83)

La dimensión sobrenatural del relato, según la cual no solo los seres animados se desplazan a través del espacio de la ciudad, sino también sus intuiciones o pensamientos, así como la posibilidad desarrollada por ciertos personajes de percibir el "ánima" de los objetos, obedece a la voluntad del narrador de incorporar en el mundo de la ficción las creencias y saberes de la cultura popular, además de su imaginario: de esa manera, a pesar de situarse en un entorno que excluye la posibilidad de escapar a la lógica de un mundo gobernado por los intereses económicos y las relaciones de poder entre los diferentes actores sociales - lo cual quedará evidenciado al final de la novela-, los sujetos de la ficción hallan en esa dimensión una vía de escape y consuelo a las agobiantes realidades en las que viven sumidos. 
Por otra parte, la representación de la ciudad en la novela se plantea a partir de la convergencia de dos órdenes espacio-temporales de naturaleza opuesta y complementaria - uno lineal y otro cíclico- que intentan, cada uno desde su perspectiva, ofrecer una explicación de los orígenes del distrito de La Victoria y de la ciudad, y de su devenir a lo largo de la historia:

Los padres del Mácalo eran inquilinos desde que se levantó la urbanización en terrenos eriazos, entonces un ejército de palurdos invadió la docena de edificios, y echó raíces sobre el cemento vertical, y las áridas puertas y ventanas de madera. La apertura de calles y plazoletas, la ampliación de La Parada, en aquel rincón de la ciudad, desató la racha de la construcción. Era una fiebre de buscadores de terrenos desocupados, extrañas gentes compraban al centavo los huertos, se apropiaban de los establos, y terribles agiotistas enarbolaron pabellones multifamiliares y agrupaciones de casuchas. $Y$ en aquel laberinto de estructuras de concreto y encofrados de fierro, la zona se fue habitando de provincianos irrelevantes, estirpes marginales, y el tropel de los callejones y antiguos tugurios. Como la mala yerba, en los intersticios de las nuevas edificaciones, se instalaron los corralones. Una muchedumbre se hacinaba en dos o tres metros cuadrados, formando viviendas de tablones, esteras y techos de colgajos. (Higa, 2007, p. 72)

Según esta primera versión, la historia de la expansión de los límites de la ciudad en La Victoria, más que responder a una planificación orquestada desde un centro de poder político, es el resultado de los intereses económicos y financieros de grupos de especuladores y agiotistas que, por el oportunismo, se apropiaron de "terrenos desocupados" para levantar más tarde un laberinto de "pabellones multifamiliares", callejones y tugurios. Destinada desde sus orígenes a ser habitada por familias de extracción popular, la historia de La Victoria se traza, por lo tanto, desde una lógica mercantilista en la que poco interesan las condiciones en que vive hacinada una muchedumbre de "provincianos irrelevantes" y "estirpes marginales"14. Ubicado en los extramuros de la ciudad, el distrito asume desde sus inicios las características de un espacio marginal y lindante con el campo en el que convergen tanto humildes familias como personajes marginales: delincuentes, matones, prostitutas, proxenetas, etcétera, todo lo cual encuentra cabida en el universo representado en la novela.

Frente a esta versión puede identificarse aquella otra que está interesada por la circularidad de la historia de Lima, más exactamente por los vestigios de la ciudad colonial; ello puede apreciarse en el discurso imaginado por el joven Matías -estudiante universitario que recorre la avenida La Colmena del centro de la ciudad junto al Pelelén y

14 El estudio antropológico de Patch (1973), realizado en los años sesenta, es decir, una década después de la época en que se desarrolla la novela de Higa (2007), también proporciona información valiosa acerca de la composición social y étnica de los habitantes de La Parada y el mundo del hampa. 
Gala, hermana del Mácalo, amigo del narrador-, a pocos metros el Hotel Crillón, símbolo de la arquitectura moderna. En la imaginación de Matías, quien pronuncia el discurso es el filósofo Tomás Monge, personaje enigmático con quien entabla una relación cercana y produce en él una extraña fascinación:

Apareció el tranvía en el jirón Lampa. [...] Lo siguieron extrañados hasta el Hotel Crillón. Ronroneaba como una cajita musical. Los fierros y la madera crujían, el viejo trole se columpiaba en los cables eléctricos. Bastó ese pequeño detalle y en la imaginación de Matías se desató el trencito amarillo, recorriendo la llanura de la plaza San Martín. [...]. Sobre el vagón de carga, se encaramaba el filósofo Tomás Monge, gritando a todo pulmón: "Aquí se unen los extremos, mira los despojos coloniales, perdieron las celosías, ya no existen las limeñas, las pacíficas fuentes, los campanarios, las prerrogativas y dignidades. Te dejo un enigma, ¿en qué horizonte arqueológico estamos nosotros los desarrapados?". (Higa, 2007, p. 151)

El discurso del filósofo puede ser interpretado como una alusión a la evocación pasatista de la ciudad presente en las narrativas herederas del legado del tradicionista Ricardo Palma: desaparecidos los vestigios del pasado, el personaje se pregunta por el presente de quienes están situados en la escala más baja de la sociedad y que protagonizarán el final de la novela, los "desarrapados". Leída por contraposición a ese pasado, el discurso de Monge revela la necesidad de cimentar un nuevo discurso narrativo sobre las ruinas del pasado: a casi medio siglo de las reflexiones de los escritores de la generación del 50 sobre la necesidad de una nueva novela que integrase las complejas realidades de la ciudad de mediados del siglo xx, en la novela de Higa (2007) retorna perfilada de un modo muy distinto la pregunta de Julio Ramón Ribeyro y sus compañeros de generación. Sin embargo, en Final del Porvenir, la representación de la ciudad se realiza desde la perspectiva de un sujeto que forma parte de un sector criollo en vías de ser desplazado hacia los nuevos márgenes de la ciudad y confundirse con las ingentes masas de provincianos migrantes. Por ello, aún subyacen en la novela algunos vestigios del pasado aludido por el discurso de Monge; la prueba más evidente de ello es el tono evocativo de la narración que contribuye a la reconstrucción del barrio de El Porvenir, visibilizada a través de los itinerarios de los personajes que, finalmente, desaparecerá para ceder paso a una nueva configuración social identificable con las pujantes barriadas ${ }^{15}$.

15 Otro rasgo que sirve para apoyar esta hipótesis reside en el hecho de que el narrador personaje hace uso de un lenguaje en el que se combinan voces y expresiones cultas con otras de origen popular, lo cual revela su extracción social y popular: "Y doña Francisquita se batía incansable, demoledora, rozagante, en sus dos metros de espacio, abría sus brazos, movilizaba su enorme humanidad [...] juntaba la canela, añadía lápices de labios, porongos de colonia, conversaba con los proveedores, sudaba si llegaban los niños, resoplaba, machacaba, insistía, pulverizaba, quebrantaba, tronchaba, colocaba el dinero en la caja, y todavía embuchaba una ración de pan con relleno, tomaba su vaso de emoliente" (Higa, 2007, p. 51). 
En la parte final de la novela, el edificio es literalmente tomado por una muchedumbre de "desarrapados", también descritos como "descamisados", cuyas casas de esteras están situadas en los "meandros del cerro San Cosme" y llegan a apreciarse desde el Mercado Mayorista:

Cuando todos dormían, sigilosamente un centenar de hombres y mujeres ingresó a la escalera, y tomó posesión de la azotea. La incursión fue simultánea en América, Giribaldi, 28 de Julio y la Bolívar. Portaban esteras, cañas, zunchos, pilotes de madera, alambras y soguillas. Nos dimos cuenta al amanecer. Nos tocaron la puerta [...]. Miramos en dirección a la azotea. Una impresionante muchedumbre se desplazaba en el parapeto. Habían levantado pequeñas chozas, las banderas flameaban en las paredes, cartelones amarrados a parantes, niños asomando por las cornisas. (Higa, 2007, p. 175)

Los descamisados son representados desde un punto de vista distante y motivan la sospecha de algunos personajes: "Matías señaló en dirección de La Parada. 'Están saqueando los puestos'. 'Creo que sí', afirmó Gala. Esperaron un rato. El estudiante añadió irónico: 'Los descamisados bajan de los cerros'” (Higa, 2007, p. 162). Más adelante, Matías intenta descifrar el significado de su presencia:

Parecía resuelto, pero no comprendía la presencia de los descamisados. Los veía acechar, trabajosamente husmeaban. Eran hombres y mujeres con sus niños a la espalda, vendían frutas y cigarros en América y Giribaldi. Le espantaba la idea de luchar contra ellos. (Higa, 2007, p. 168)

Finalmente, entiende que el enfrentamiento entre inquilinos y descamisados es inútil y que el enemigo común de ambos es el Banco Popular: "Tienes que comprender. No debemos pelear contra ellos. Tenemos que juntarnos a ellos. Somos compañeros de un mismo barco" (p. 183) ${ }^{16}$. La conclusión de Matías coincide con el desenlace de la novela, con lo cual el discurso de Monge cobra un nuevo sentido: una vez desalojados, los inquilinos pasarán a integrarse en la clase de los desarrapados, obligados por las tropas del ejército a instalarse en los nuevos márgenes situados en el distrito de Comas ${ }^{17}$. De este modo, se enuncia un mensaje muy claro acerca de la lucha de clases en el seno de una sociedad en la que priman los intereses económicos de una élite representada por un Estado que gobierna de espaldas a las necesidades de sus ciudadanos.

16 En la primera parte de la novela, don Pepito Vidalón, al discutir de política en el billar Monsalve, “llamaba oligarca al nuevo presidente, hijo de la pituquería, propietario del Banco Popular, rodeado de corrompidos, mientras el sufrido pueblo se moría de hambre" (p. 89).

17 La invasión de Comas se produce en 1958: “'Desde el inicio de su gobierno, Prado enfrentó varias importantes invasiones de tierras. La más famosa fue la de Comas en 1958. Los informes periodísticos de la época indican que unas 10000 personas llegaron a unas tierras ubicadas al norte de la ciudad en unas cuarentaiocho horas'" (Dietz, citado por Fernández-Maldonado, 2013, p. 61). 
A pesar del lapso temporal que separa la publicación de las novelas Barrio de broncas, de José Antonio Bravo, y Final del Porvenir, de Augusto Higa, es posible reconocer en ellas una serie de elementos comunes que permiten agruparlas como representaciones del espacio del barrio cuyos contornos aparecen claramente perfilados, en contraste con la imagen expansiva e indiferenciada de la urbe. Aun cuando la violencia y los conflictos sociales prevalecen como elementos disruptivos que dan cuenta de las contradicciones del proyecto modernizador de la ciudad, en ambas la memoria desempeña un papel importante en la recuperación de ciertos espacios fuertemente arraigados en los personajes. Este síntoma persiste como una huella indeleble de la resistencia del sujeto a la violenta transformación y expansión de la configuración y los límites de la ciudad: en tal sentido, los textos examinados son portadores de las tensiones que operan en el seno de una sociedad que asume una posición contradictoria ante la modernidad, pero que también debe hacer frente a las nuevas realidades sociales que cuestionan el modelo del progreso. Cercada por la imperiosa presencia de los migrantes y sus urgentes demandas, la Lima representada en ambas novelas se debate por la supervivencia de un mundo que indefectiblemente está condenado a desaparecer.

\section{REFERENCIAS}

Bravo, J. A. (1996). Barrio de broncas (Análisis e interpretación de la novela de M. Velando, y estudio del vocabulario de E. Foley). Bruño.

Carrillo, E. A. (2007). Cartas de una turista. En M. A. Rodríguez Rea (Ed.), Obras reunidas (pp. 21-100). Pontificia Universidad Católica del Perú.

Fernández-Maldonado, A. M. (2013). La marcha de las barriadas en la segunda mitad del siglo xx. En C. Aguirre y A. Panfichi (Eds.), Lima, siglo xx. Cultura, socialización y cambio (pp. 57-81). Pontificia Universidad Católica del Perú, Fondo Editorial.

Higa, A. (2007). Final del Porvenir. Editorial San Marcos.

Patch, R. W. (1973). La Parada. Estudio de un mundo alucinante. Mosca Azul.

Pérez Porto, J., y Gardey, A. (2013). Definición de barrio. Definición.de. https://definicion. de/barrio/

Prieto Sánchez, R. (2009). Guía secreta. Barrios rojos y casas de prostitución en la historia de Lima. Centro Cultural de España; Universidad Ricardo Palma.

Ramón Joffré, G. (2014). El Inca indica Huatica. En El neoperuano. Arqueología, estilo nacional y paisaje urbano en Lima, 1910-1940 (pp. 73-88). Municipalidad Metropolitana de Lima; Sequilao Editores.

Reynoso, 0. (2011). Los inocentes. Estruendomudo. 